\title{
Antimicrobial resistance patterns and prevalence of class 1 and 2 integrons in Shigella flexneri and Shigella sonnei isolated in Uzbekistan
}

\author{
Ruslan S Madiyarov ${ }^{1}$ Amir M Bektemirov ${ }^{1}$, Gulnara A Ibadova ${ }^{1}$, Gulnara K Abdukhalilova ${ }^{1}$, Aybek V Khodiev*, \\ Ladaporn Bodhidatta ${ }^{2}$, Orntipa Sethabutr ${ }^{2}$, Carl J Mason ${ }^{2}$
}

\begin{abstract}
Background: Shigella is a frequent cause of bacterial dysentery in the developing world. Treatment with effective antibiotics is recommended for shigellosis, but options become limited due to globally emerging resistance. One of the mechanisms for the development of resistance utilizes integrons. This study described the antibiotic susceptibility and the presence of class 1 and 2 integrons in S. flexneri and S. sonnei isolated in Uzbekistan.

Results: We studied 31 isolates of S. flexneri and 21 isolates of S. sonnei isolated in Uzbekistan between 1992 and 2007 for the susceptibility or resistance to ampicillin (Am), chloramphenicol (Cl), tetracycline (Te), co-trimoxazole (Sxt), kanamycin (Km), streptomycin (Str), gentamicin (Gm), cefazolin (Czn), cefoperazone (Cpr), cefuroxime (Cur), ceftazidime (Ctz), nalidixic acid (NA) and ciprofloxacin (Cip). Am/Str/Cl/Te and Am/Str/Cl/Te/Sxt resistance patterns were found most frequently in S. flexneri. Single isolates were resistant to aminoglycoside, quinolones and cephalosporins. The resistance patterns were different in the two species. Integrons were detected in $93.5 \%$ of $S$. flexneri (29/31) and $81.0 \%$ of S. sonnei (17/21) isolates. In addition, $61.3 \%$ of S. flexneri (19/31) isolates and $19.0 \%$ of S. sonnei (4/21) isolates carried both classes of integrons. In $29.0 \%$ of S. flexneri (9/31) isolates, only class 1 integrons were identified. In S. flexneri isolates, the presence of class 1 integrons was associated with resistance to ampicillin and chloramphenicol. Only Class 2 integrons were present in $61.9 \%$ of S. sonnei (13/21) isolates.

Conclusions: Our study documents antibiotic resistance among Shigella spp. in Uzbekistan. Ninety percent of Shigella strains were resistant to previously used antibiotics. Differences among S. flexneri and S. sonnei isolates in patterns of antimicrobial resistance to routinely used shigellosis antibiotics were observed. The majority of $S$. flexneri were resistant to ampicillin, chloramphenicol, tetracycline and streptomycin. Class 1 and 2 integrons were widely present in these Shigella strains. Resistance to ampicillin/chloramphenicol was associated with the presence of class 1 integrons. Though several mechanisms are possible, the resistance of Shigella isolates to ampicillin/ chloramphenicol may be associated with the expression of genes within class 1 integrons.
\end{abstract}

\section{Background}

Shigellosis is an acute enteric infection caused by Shigella species and manifested by diarrhea. Shigellosis is endemic to many developing countries, and also occurs in epidemics causing considerable morbidity and mortality $[1,2]$. It was reported that more than 140 million cases of shigellosis occurred worldwide, with 600,000 people dying annually; $60 \%$ of the deaths were seen in children

\footnotetext{
*Correspondence: akhodiev@gmail.com

'Research Institute of Epidemiology, Microbiology and Infectious Diseases,

Tashkent 100133, Republic of Uzbekistan

Full list of author information is available at the end of the article
}

under the age of 5 [3]. S. flexneri is the most commonly isolated Shigella species in the developing world and the most frequent cause of bacterial dysentery. In countries with improved water supply and sanitation, the predominant species is S. sonnei. Antimicrobial agents are recommended for the treatment of shigellosis; however, increasing antimicrobial resistance in the Shigella spp. has been reported worldwide $[1,2]$. Shigella strains have obtained resistance to some of the most widely used antibiotics, resulting in reduced efficacies of antimicrobial therapy [2,4-6]. One of the mechanisms of resistance development is the horizontal transfer of genetic factors. 
These include R-plasmids, transposons, integrons and genetic "islands", which can transfer within a taxon $[7,8]$. Integrons, discovered in the 1980s, are able to horizontally transfer genes; this is common for Enterobacteriaceae $[9,10]$. Integrons typically consist of an intI gene, which encodes for integrase that catalyzes the incorporation or excision of gene cassettes by site-specific recombination; a recombination site attI; and a promoter responsible for the expression of inserted gene cassettes. Integrons have been extensively studied in clinical environments due to their association with other mobile genetic elements and multi-resistance phenotypes. There are 4 classes of integrons that are distinguishable by the integrase enzymes [11,12]. Class 1 and 2 integrons are the most widespread among the Enterobacteriaceae, and the correlation between the presence of integrons and resistance to some antimicrobial agents has been demonstrated [13]. There are several publications dedicated to the study of integrons in Shigella spp. in different regions; however, Central Asia was not covered in these studies [14-16]. The widespread prevalence of polyresistant enteric bacteria necessitates the consistent surveillance for antimicrobial resistance in Shigella spp. to select effective antimicrobial agents. The purpose of this study was to analyze antimicrobial susceptibility and the presence of integrons in S. flexneri and S. sonnei isolated in Uzbekistan.

\section{Results and Discussion}

We studied 31 isolates of $S$. flexneri and 21 isolates of $S$. sonnei that were isolated in Uzbekistan between 1992 and 2007 for the susceptibility or resistance to ampicillin (Am), chloramphenicol $(\mathrm{Cl})$, tetracycline $(\mathrm{Te})$, co-trimoxazole (Sxt), kanamycin $(\mathrm{Km})$, streptomycin (Str), gentamicin $(\mathrm{Gm})$, cefazolin $(\mathrm{Czn})$, cefoperazone $(\mathrm{Cpr})$, cefuroxime (Cur), ceftazidime (Ctz), nalidixic acid (NA) and ciprofloxacin (Cip). All Shigella isolates were resistant to streptomycin. Most of the isolates were resistant to ampicillin, chloramphenicol and tetracycline (Table 1). Among the $S$. flexneri isolates, the most prevalent antimicrobial agent resistance patterns were $\mathrm{Am} / \mathrm{Str} / \mathrm{Cl} / \mathrm{Te}$ and $\mathrm{Am} / \mathrm{Str} / \mathrm{Cl} / \mathrm{Te} /$ Sxt. The most common S. sonnei antimicrobial agent resistance patterns were Str, Str/Sxt/Te and Str/Te (Table 2).

Our data revealed differences in antimicrobial agent resistance patterns among S. flexneri and S. sonnei for the routinely used antimicrobial agents. The S. sonnei isolates retained high sensitivity to ampicillin and chloramphenicol but also exhibited higher resistance to cotrimoxazole than the S. flexneri isolates did. However, we identified one S. flexneri isolate that resistant to all tested cephalosporins and one S. sonnei isolate resistant to nalidixic acid and the cephalosporins.

Ampicillin, chloramphenicol and tetracycline were the medications of choice in Uzbekistan for the treatment of shigellosis. Currently, $90 \%$ of clinical isolates of S. flexneri, the most common cause of shigellosis in Uzbekistan, have lost the natural susceptibility to these medications. In addition, the appearance of strains resistant to quinolones and cephalosporins, which are recommended for treatment, is an emerging problem that will require new approaches for antimicrobial therapy of shigellosis [17]. However, in our study, we observed high in vitro activity of quinolones and cephalosporins, making them the recommended drugs of choice for the treatment of shigellosis in Uzbekistan $[2,18]$.

PCR studies for integrons revealed the presence of both class 1 and class 2 integrons in S. flexneri and S. sonnei (Tables 2 and 3). Integrons were detected in $93.5 \%$ of S. flexneri $(29 / 31)$ and $81.0 \%$ of S. sonnei (17/ 21 ) isolates. In $61.3 \%$ of $S$. flexneri (19/31) isolates, both classes of integrons were identified, whereas only class 1 integrons were identified in $29.0 \%$ of S. flexneri (9/31) isolates. Within the $S$. sonnei isolates, class 2 integrons alone were identified in $61.9 \%$ of isolates $(13 / 21)$ and both class 1 and 2 integrons were identified in $19.0 \%$ of isolates (4/21). The prevalence of class 2 integrons in $S$. sonnei is in agreement with other published data $[16,19]$. We did not identify S. sonnei isolates harboring only class 1 integrons.

The high prevalence of class 1 and class 2 integrons in this series of Shigella isolates as well as high prevalence of resistance to the "older" antibiotics: ampicillin, chloramphenicol, tetracycline, and streptomycin, makes statistical associations between phenotypic antimicrobial resistance and the presence of integrons difficult to interpret. In this series of isolates, for example, resistance to streptomycin was detected in all 52 Shigella isolates yet two S. flexneri and four S. sonnei isolates had no integrons detected (Table 3). Yet, in all $28 \mathrm{~S}$. flexneri isolates where class 1 integrons were detected, resistance to both chloramphenicol and ampicillin was noted, and those $3 \mathrm{~S}$. flexneri isolates lacking class 1 integrons were susceptible to both. Although cassettes including resistance genes to ampicillin, chlorampheni$\mathrm{col}$, and streptomycin have all been reported to commonly be present in integrons, in the absence of sequencing augmented by conjugation experiments, it is not possible to confirm the location of the active resistance genes in integrons $[11,15,18]$.

\section{Conclusions}

Our study confirms the circulation of Shigella flexneri and Shigella sonnei strains that are resistant to widely used antimicrobial agents and significant prevalence of integrons in Shigella spp. circulating in Uzbekistan. Though several mechanisms are possible, the resistance of Shigella isolates to ampicillin/chloramphenicol may 
Table 1 Antimicrobial agent susceptibilities and MIC ranges of Shigella isolates from Uzbekistan

\begin{tabular}{|c|c|c|c|c|c|c|c|c|c|c|c|}
\hline \multirow{3}{*}{$\begin{array}{l}\text { Antimicrobial } \\
\text { agent* }\end{array}$} & \multicolumn{4}{|c|}{ S. flexneri $(n=31)$} & \multicolumn{4}{|c|}{ S. sonnei $(n=21)$} & \multicolumn{3}{|c|}{ Breakpoint values $(\mu \mathrm{g} / \mathrm{ml}) \|$} \\
\hline & \multirow{2}{*}{$\begin{array}{c}\text { Resistant } \\
\text { isolates } \\
\text { No (\%) }\end{array}$} & \multicolumn{3}{|c|}{$\mathrm{MIC}^{\dagger}(\mu \mathrm{g} / \mathrm{ml})$} & \multirow{2}{*}{$\begin{array}{c}\text { Resistant } \\
\text { isolates } \\
\text { No (\%) }\end{array}$} & \multicolumn{3}{|c|}{ MIC $(\mu \mathrm{g} / \mathrm{ml})$} & \multirow[b]{2}{*}{$\mathbf{R}$} & \multirow[b]{2}{*}{1} & \multirow[b]{2}{*}{$\mathrm{S}$} \\
\hline & & Range & $\mathrm{MIC}_{50}{ }^{\neq}$ & $\mathrm{MIC}_{90}{ }^{\S}$ & & Range & $\mathrm{MIC}_{50}$ & $\mathrm{MIC}_{90}$ & & & \\
\hline Am & $28(90.4)$ & $2-512$ & 256 & 512 & $1(4.8)$ & $4-512$ & 4 & 8 & $\geq 32$ & 16 & $\leq 8$ \\
\hline $\mathrm{Cl}$ & $28(90.4)$ & $4-256$ & 128 & 256 & $1(4.8)$ & $2-256$ & 8 & 8 & $\geq 32$ & 16 & $\leq 8$ \\
\hline $\mathrm{Te}$ & 29(93.5) & $1-256$ & 128 & 128 & $7(66.7)$ & $1-256$ & 128 & 256 & $\geq 16$ & 8 & $\leq 4$ \\
\hline Sxt & $10(32.3)$ & $0.5-128$ & $2 / 38$ & $128 / 2432$ & $6(62)$ & $0.5-128$ & $128 / 2432$ & $128 / 2432$ & $\geq 4 / 76$ & N/A & $\leq 2 / 38$ \\
\hline $\mathrm{Km}$ & $2(6.5)$ & $4-128$ & 8 & 16 & $1(4.8)$ & $4-64$ & 8 & 8 & $\geq 64$ & 32 & $\leq 16$ \\
\hline Str & $31(100)$ & $64-256$ & 256 & 256 & $21(100)$ & 256 & 256 & 256 & $\geq 64$ & 32 & $\leq 16$ \\
\hline $\mathrm{Gm}$ & $1(3.2)$ & $2-32$ & 4 & 4 & $2(9.5)$ & $1-64$ & 2 & 2 & $\geq 16$ & 8 & $\leq 4$ \\
\hline Czn & $1(3.2)$ & $0.5-32$ & 2 & 4 & $O(0.0)$ & $1-4$ & 2 & 2 & $\geq 32$ & 16 & $\leq 8$ \\
\hline Cpr & $1(3.2)$ & $0.03-64$ & 0.25 & 0.5 & $0(0.0)$ & $0.12-0.5$ & 0.12 & 0.25 & $\geq 64$ & 32 & $\leq 16$ \\
\hline Cur & $1(3.2)$ & $1-64$ & 4 & 4 & $0(0.0)$ & $1-4$ & 4 & 4 & $\geq 32$ & 16 & $\leq 8$ \\
\hline Ctz & $1(3.2)$ & $0.06-64$ & 0.12 & 0.25 & $O(0.0)$ & $0.06-0.5$ & 0.12 & 0.25 & $\geq 32$ & 16 & $\leq 8$ \\
\hline NA & $0(0.0)$ & $0.12-0.5$ & 0.12 & 0.5 & $1(4.8)$ & $0.12-32$ & 0.12 & 0.25 & $\geq 32$ & N/A & $\leq 16$ \\
\hline Cip & $0(0.0)$ & $0.008-0.016$ & 0.008 & 0.016 & $1(4.8)$ & $0.004-4$ & 0.008 & 0.016 & $\geq 4$ & 2 & $\leq 1$ \\
\hline
\end{tabular}

* Am = ampicillin, $\mathrm{Cl}=$ chloramphenicol, Te = tetracycline, Sxt = co-trimoxazole (trimethoprim- sulfamethoxazole), $\mathrm{Km}=$ kanamycin, Str = streptomycin, Gm = gentamicin, Czn = cefazolin, $\mathrm{Cpr}=$ cefoperazone, Cur = cefuroxime, Ctz = ceftazidime, NA = nalidixic acid, Cip = ciprofloxacin

$+\mathrm{MIC}=$ Minimal inhibitory concentration; $\neq \mathrm{MIC}_{50}=\mathrm{MIC}$ inhibiting $50 \%$ of isolates; $\S \mathrm{MIC}_{90}=$ MIC inhibiting $90 \%$ of isolates; $\|$ - intermediate resistant isolates were considered as resistant

be associated with the expression of genes within class 1 integrons. Cephalosporins and quinolones retain high in vitro activity, but emergence of strains resistant to all tested cephalosporins and other antimicrobials will require continued routine monitoring of the antimicrobial resistance of Shigella spp. in Uzbekistan.

\section{Methods}

Isolates and serotyping

All Shigella isolates were provided by the "National Collection of Pathogens I-II Group" of the Ministry of Health of

Table 2 Antimicrobial agent resistance patterns of S. flexneri and S. sonnei isolates from Uzbekistan

\begin{tabular}{|c|c|c|}
\hline Antimicrobial resistance pattern* & $\begin{array}{c}\text { S. flexneri } \\
(\mathrm{n}=31) \\
\text { No }(\%)\end{array}$ & $\begin{array}{c}\text { S. sonnei } \\
(\mathrm{n}=21) \\
\text { No }(\%)\end{array}$ \\
\hline $\mathrm{Am} / \mathrm{Cl} / \mathrm{Str} / \mathrm{Te}$ & $19(61.3)$ & $0(0.0)$ \\
\hline $\mathrm{Am} / \mathrm{Cl} / \mathrm{Str} / \mathrm{S} x \mathrm{t} / \mathrm{Te}$ & $8(25.8)$ & $0(0.0)$ \\
\hline $\mathrm{Am} / \mathrm{Cl} / \mathrm{Str} / \mathrm{S} x \mathrm{t} / \mathrm{Te} / \mathrm{Czn} / \mathrm{Cpr} / \mathrm{Cur} / \mathrm{Ctz} / \mathrm{Gm} / \mathrm{Km}$ & $1(3.2)$ & $0(0.0)$ \\
\hline $\mathrm{Km} / \mathrm{Str} / \mathrm{S} x \mathrm{t}$ & $1(3.2)$ & $0(0.0)$ \\
\hline Str/Sxt & $2(6.4)$ & $0(0.0)$ \\
\hline $\mathrm{Str} / \mathrm{S} x \mathrm{t} / \mathrm{Te}$ & $0(0.0)$ & $10(47.6)$ \\
\hline Str & $0(0.0)$ & $6(28.6)$ \\
\hline Str/Te & $0(0.0)$ & $2(9.5)$ \\
\hline $\mathrm{Am} / \mathrm{Cl} / \mathrm{Str} / \mathrm{S} x \mathrm{t} / \mathrm{Gm} / \mathrm{Km}$ & $0(0.0)$ & $1(4.8)$ \\
\hline $\mathrm{Gm} / \mathrm{Str} / \mathrm{S} x \mathrm{t} / \mathrm{Te}$ & $0(0.0)$ & $1(4.8)$ \\
\hline NA/Cip/Str/Sxt/Te & $0(0.0)$ & $1(4.8)$ \\
\hline
\end{tabular}

* Am = ampicillin, $\mathrm{Cl}=$ chloramphenicol, $\mathrm{Te}=$ tetracycline, Sxt = cotrimoxazole (trimethoprim- sulfamethoxazole), $\mathrm{Km}=$ kanamycin, $\mathrm{Str}=$ streptomycin, $\mathrm{Gm}=$ gentamicin, $\mathrm{Czn}=$ cefazolin, $\mathrm{Cpr}=$ cefoperazone, $\mathrm{Cur}=$ cefuroxime, $\mathrm{Ctz}=$ ceftazidime, $\mathrm{NA}=$ nalidixic acid, $\mathrm{Cip}=$ ciprofloxacin the Republic of Uzbekistan. In total, 52 isolates of S. flexneri and $S$. sonnei were studied (31 and 21 isolates, respectively). All strains were isolated from stool samples of patients with bacterial dysentery in Uzbekistan between 1992 and 2007. The isolation and confirmation of Shigella species were performed by following WHO recommendations [20]. Stool samples were inoculated on Endo agar and Salmonella-Shigella agar (SS agar) (Merck, Darmstadt, Germany). After overnight incubation at $37^{\circ} \mathrm{C}$, the Endo agar and SS agar plates were checked for non-lactose-fermenting colonies. Colonies characteristically resembling Shigella spp. were differentiated from other non-lactose-fermenting enteric pathogens by inoculating on Kligler iron agar (KIA agar) (HiMedia Laboratories Pvt. Ltd., Mumbai, India) for typical reactions [20]. Biochemical and serological typing of Shigella spp. were performed by standard methods with specific antisera [21]. Prior to testing, each isolate was grown on a Mueller-Hinton agar (MHA) plate (HiMedia Laboratories Pvt. Ltd., Mumbai, India), incubated overnight at $37^{\circ} \mathrm{C}$ and subsequently checked for auto-agglutination in saline. Specimens grown on the 18-20 hrs agar plate were used to carry out agglutination tests according to the manufacturers' instructions (SPBNIIVS, Sankt-Petersburg, Russian Federation). In cases where no agglutination was observed with any of the commercial antisera, the isolates were tested for the presence of heat-labile inhibitory substances as recommended [21]. Briefly, a colony was picked with loop and dissolved in sterile normal saline to 0.5 McFarland standards, heated at $100^{\circ} \mathrm{C}$ for $60 \mathrm{~min}$, cooled and centrifuged; and resulting pellets were used for testing. For the slide agglutination test, the agglutination of prepared 
Table 3 Presence of integrons in Shigella isolates from Uzbekistan and sensitivity/resistance to selected antimicrobial agents

\begin{tabular}{|c|c|c|c|c|c|c|c|c|c|c|}
\hline \multirow[t]{2}{*}{ Isolate no. } & \multirow[t]{2}{*}{ Species } & \multicolumn{7}{|c|}{ Antimicrobial agent* } & \multicolumn{2}{|c|}{$\begin{array}{c}\text { Integron } \\
\text { class }\end{array}$} \\
\hline & & $\mathrm{Am}$ & $\mathrm{Cl}$ & $\mathrm{Gm}$ & $\mathrm{Km}$ & Sxt & $\mathrm{Te}$ & Str & 1 & 2 \\
\hline 1410 & S. flexneri 1a & $R$ & $R$ & S & S & $S$ & $\mathrm{R}$ & $R$ & + & - \\
\hline 1806 & S. flexneri $1 \mathrm{~b}$ & $\mathrm{R}$ & $\mathrm{R}$ & S & S & S & $\mathrm{R}$ & R & + & + \\
\hline 2316 & S. flexneri 1c & R & R & S & S & S & $\mathrm{R}$ & $\mathrm{R}$ & + & - \\
\hline $1461 / 542$ & S. flexneri $2 \mathrm{a}$ & $\mathrm{R}$ & R & S & S & S & $\mathrm{R}$ & $\mathrm{R}$ & + & - \\
\hline $2125 / 947$ & S. flexneri 2a & $\mathrm{R}$ & $\mathrm{R}$ & S & s & S & $R$ & $\mathrm{R}$ & + & - \\
\hline $2864 / 574$ & S. flexneri $2 \mathrm{a}$ & $\mathrm{R}$ & $\mathrm{R}$ & S & S & $R$ & $\mathrm{R}$ & $\mathrm{R}$ & + & + \\
\hline $3104 / 355$ & S. flexneri 2a & $\mathrm{R}$ & R & S & S & $\mathrm{R}$ & $\mathrm{R}$ & $\mathrm{R}$ & + & + \\
\hline $116 / 944$ & S. flexneri $2 \mathrm{a}$ & $\mathrm{R}$ & $\mathrm{R}$ & S & S & $\mathrm{R}$ & $\mathrm{R}$ & $\mathrm{R}$ & + & + \\
\hline $3160 / 383$ & S. flexneri 2a & R & $\mathrm{R}$ & S & S & R & $R$ & $R$ & + & - \\
\hline $4036 / 750$ & S. flexneri $2 \mathrm{a}$ & $R$ & R & S & S & S & $R$ & $\mathrm{R}$ & + & + \\
\hline 33 & S. flexneri $2 \mathrm{a}$ & $R$ & R & S & S & S & $\mathrm{R}$ & $\mathrm{R}$ & + & + \\
\hline 430 & S. flexneri 2a & $R$ & R & S & S & S & $\mathrm{R}$ & $R$ & + & - \\
\hline 525 & S. flexneri $2 \mathrm{a}$ & $\mathrm{R}$ & R & S & S & $\mathrm{R}$ & $R$ & $\mathrm{R}$ & + & + \\
\hline 842 & S. flexneri $2 \mathrm{a}$ & R & R & S & S & $R$ & $\mathrm{R}$ & $\mathrm{R}$ & + & + \\
\hline 1773 & S. flexneri $2 \mathrm{a}$ & $R$ & $R$ & S & S & S & $R$ & $\mathrm{R}$ & + & + \\
\hline 1771 & S. flexne & $R$ & R & S & S & S & $R$ & R & + & + \\
\hline 1807 & $i 2 \mathrm{a}$ & R & R & S & S & S & $R$ & R & + & + \\
\hline 1832 & S. flexneri 2a & $R$ & R & S & S & R & $R$ & $R$ & + & + \\
\hline 2011 & $i 2 \mathrm{a}$ & $R$ & R & S & S & S & $\mathrm{R}$ & $\mathrm{R}$ & + & + \\
\hline 2344 & $2 a$ & $R$ & $R$ & S & S & S & R & R & + & + \\
\hline 2215/ & S. flex & S & S & S & R & R & $S$ & $\mathrm{R}$ & - & + \\
\hline 737 & S. flexneri $2 a$ & S & S & S & S & S & $\mathrm{R}$ & $\mathrm{R}$ & - & - \\
\hline 187 & S. $f$ & $R$ & R & S & S & $\mathrm{R}$ & $R$ & $\mathrm{R}$ & + & + \\
\hline $4297 / 4$ & S. fle, & $R$ & R & S & S & S & $\mathrm{R}$ & $\mathrm{R}$ & + & + \\
\hline 1874 & ri 3a & $R$ & R & S & S & S & $\mathrm{R}$ & $\mathrm{R}$ & + & + \\
\hline 769 & S. flexneri 3b & R & R & S & S & S & $\mathrm{R}$ & $\mathrm{R}$ & + & - \\
\hline 1544 & S. flex & $R$ & R & R & R & $\mathrm{R}$ & $R$ & R & + & + \\
\hline 2376 & S. fle, & $R$ & $R$ & S & S & S & $\mathrm{R}$ & $\mathrm{R}$ & + & - \\
\hline $3049 / 4$ & S. flexn & $R$ & R & S & S & S & $\mathrm{R}$ & $R$ & + & + \\
\hline 2078 & S. flexr & $\mathrm{R}$ & $\mathrm{R}$ & S & S & S & R & R & + & - \\
\hline $2126 / 472$ & S. flexneri 6 & S & S & S & S & S & S & $\mathrm{R}$ & - & - \\
\hline $344 / 1899$ & & S & S & S & S & S & $S$ & $\mathrm{R}$ & - & - \\
\hline & & S & S & S & S & $\mathrm{R}$ & $\mathrm{R}$ & $\mathrm{R}$ & + & + \\
\hline $358 / 477$ & S. sor & S & S & S & S & S & S & $\mathrm{R}$ & - & + \\
\hline $333 / 1755$ & S. sonnei & $S$ & S & S & S & $S$ & $\mathrm{R}$ & $\mathrm{R}$ & + & + \\
\hline $359 / 400$ & S. sonnei & $S$ & S & S & S & $S$ & $S$ & $\mathrm{R}$ & - & + \\
\hline & & S & S & S & S & R & $\mathrm{R}$ & $\mathrm{R}$ & - & + \\
\hline $766 / 601$ & S. sonnei & S & S & S & S & S & $\mathrm{R}$ & $\mathrm{R}$ & & - \\
\hline $1159 / 107$ & S. sonnei & $\mathrm{S}$ & S & S & S & $\mathrm{R}$ & $\mathrm{R}$ & $\mathrm{R}$ & - & - \\
\hline 1201/1982 & & S & S & S & S & $\mathrm{R}$ & $\mathrm{R}$ & $R$ & - & + \\
\hline 1316/152 & & S & S & S & S & S & $S$ & $\mathrm{R}$ & - & + \\
\hline $1805 / 146$ & S. sonnei & $S$ & S & S & S & $\mathrm{R}$ & $R$ & $R$ & + & + \\
\hline $1849 / 760$ & & S & S & S & S & $S$ & $S$ & $\mathrm{R}$ & - & + \\
\hline $2939 / 5116$ & & S & S & S & S & S & $S$ & $R$ & - & - \\
\hline $1553 / 3$ & & $\mathrm{R}$ & $R$ & R & R & $\mathrm{R}$ & $S$ & R & + & + \\
\hline $1711 / 2$ & S. sonnei & $S$ & S & $S$ & S & $\mathrm{R}$ & $\mathrm{R}$ & $\mathrm{R}$ & - & + \\
\hline $1745 / 3$ & & $S$ & S & S & S & $\mathrm{R}$ & $\mathrm{R}$ & $\mathrm{R}$ & - & + \\
\hline $4166 / 149$ & S. sonnei & S & $S$ & $S$ & $S$ & $\mathrm{R}$ & $\mathrm{R}$ & $\mathrm{R}$ & - & + \\
\hline
\end{tabular}

Table 3 Presence of integrons in Shigella isolates from Uzbekistan and sensitivity/resistance to selected antimicrobial agents (Continued)

\begin{tabular}{|c|c|c|c|c|c|c|c|c|c|c|}
\hline 4336/671 & S. sonnei & $S$ & S & S & $S$ & $R$ & $R$ & $R$ & - & + \\
\hline 4340/966 & S. sonnei & $S$ & $S$ & $S$ & S & $\mathrm{R}$ & $\mathrm{R}$ & $R$ & - & + \\
\hline 4342/1199 & S. sonnei & S & S & S & S & $\mathrm{R}$ & $\mathrm{R}$ & $\mathrm{R}$ & - & + \\
\hline 4345/199 & S. sonnei & $S$ & S & $R$ & $S$ & $\mathrm{R}$ & $R$ & $R$ & - & + \\
\hline
\end{tabular}

* $\mathrm{S}=$ susceptible, $\mathrm{R}=$ resistant, ${ }^{*} \mathrm{Am}=$ ampicillin, $\mathrm{Cl}=$ chloramphenicol, $\mathrm{Te}=$ tetracycline, Sxt = co-trimoxazole (trimethoprim- sulfamethoxazole), $\mathrm{Km}=$ kanamycin, Str = streptomycin, $\mathrm{Gm}=$ gentamicin, $\mathrm{Czn}=$ cefazolin, $\mathrm{Cpr}=$ cefoperazone, Cur = cefuroxime, $\mathrm{Ctz}=$ ceftazidime, $\mathrm{NA}=$ nalidixic acid, $\mathrm{Cip}=$ ciprofloxacin

samples with antisera was observed against a black background. The slide was tilted for $1 \mathrm{~min}$ and agglutination scores were graded from 0 to 4 ( 0 -no agglutination after 1 min, 1-weak agglutination after 3 min, 2-weak agglutination after $1 \mathrm{~min}$, 3-agglutination within $1 \mathrm{~min}$, 4-visible rapid agglutination right after addition of antisera). Only 3-4 scored agglutinated samples were considered as positive.

\section{Antimicrobial susceptibility test}

Antimicrobial susceptibility testing for Minimal Inhibitory Concentration (MIC50 and MIC90) was performed by a serial dilution method on solid agar, and the Minimal Inhibitory Concentration was determined on MHA according to Clinical and Laboratory Standards Institute and the "Guidelines for susceptibility testing of microorganisms to antimicrobial agents" (Ministry of Health, Russian Federation) [22-24].

Briefly, MHA plates with different concentrations of antimicrobial agents ((HiMedia Laboratories Pvt. Ltd., Mumbai, India) were prepared. Plates without antimicrobial agents were prepared for growth quality control. MHA was poured into $90-\mathrm{mm}$ plates on $3 \mathrm{~mm}$ depth. Once prepared, plates were stored at $4^{\circ} \mathrm{C}$ and used within 2 days. Approximately four colonies of overnight incubated subcultures were inoculated into $4 \mathrm{ml}$ of Nutrient broth (HiMedia Laboratories Pvt. Ltd., Mumbai, India). After $4 \mathrm{~h}$ of incubation at $37^{\circ} \mathrm{C}$, bacterial suspension was adjusted to 0.5 McFarland standards. A $100 \mu \mathrm{l}$ volume of this suspension was added to $900 \mu \mathrm{l}$ of broth to produce a concentration of approximately $1 \times$ $10^{7} \mathrm{CFU} / \mathrm{ml}$. Plates were inoculated with metal loop (approximately $1 \mu \mathrm{l}$ of bacterial suspension resulting spot of $5 \mathrm{~mm}$ in diameter) with $1 \times 10^{4} \mathrm{CFU} / \mathrm{ml}$ in final inoculum. Plates were incubated for $18 \mathrm{~h}$ at $35^{\circ} \mathrm{C}$ under atmospheric conditions. Growth was recorded positive if at least one colony was observed at the inoculation site [22-24]. Isolates were identified as resistant or susceptible $(\mathrm{R} / \mathrm{S})$. Intermediate susceptibility was categorized as resistant. Reference strains of E. coli (ATCC 25922), S. aureus (ATCC 25923) and P. aeruginosa (ATCC 27853) were used for media and reagent quality control. 


\section{Integron detection}

Bacterial DNA was extracted from overnight incubation of pure cultures by heating in a water bath at $96^{\circ} \mathrm{C}$ for $20 \mathrm{~min}$. After centrifugation, supernatants were stored at $-20^{\circ} \mathrm{C}$ prior to PCR reactions. Primers (Operon Biotechnologies $\mathrm{GmbH}$, Cologne, Germany) int1L (5'ACATGTGATGGCGACGCACGA-3') and int1R (5'ATTTCTGTCCTGGCTGGCGA-3') were used for amplification of class 1 integrase (initial denaturation at $94^{\circ} \mathrm{C}$ for $10 \mathrm{~min}$; 35 cycles of $94^{\circ} \mathrm{C}$ for $1 \mathrm{~min}, 60^{\circ} \mathrm{C}$ for 1 min, $72^{\circ} \mathrm{C}$ for $1 \mathrm{~min}$; final elongation at $72^{\circ} \mathrm{C}$ for 10 min) [18]; Primers int2F (5'-GTAGCAAACGAGTGACGAAATG-3') and int2R (5'-CACGGATATGCGACAAAAAGGT-3') were used for amplification of class 2 integrase (initial denaturation at $95^{\circ} \mathrm{C}$ for $10 \mathrm{~min}$; 35 cycles of $95^{\circ} \mathrm{C}$ for $50 \mathrm{sec}, 58^{\circ} \mathrm{C}$ for $1 \mathrm{~min}, 72^{\circ} \mathrm{C}$ for $1 \mathrm{~min} 10 \mathrm{sec}$; final elongation at $72^{\circ} \mathrm{C}$ for $10 \mathrm{~min}$ ) [25]. The amplification was performed with the FailSafe ${ }^{\mathrm{Tx}} \mathrm{PCR}$ System (EPICENTRE Biotechnologies, Madison, WI, USA) in a $25.0 \mu \mathrm{l}$ reaction volume on a Thermo Px2 thermal cycler (Thermo Fisher Scientific Inc., Waltham, MA, USA) following manufacturer recommendations. PCR products were detected by ethidium bromine staining after electrophoresis in 1.5\% agarose gels (SERVA Electrophoresis GmbH, Heidelberg, Germany), with DNA ladders (pUC19DNA/Mspl-Silex, Moscow, Russian Federation; M100-Galart-diagnosticum, Moscow, Russian Federation) to determine band sizes. The expected band sizes were approximately 569 bp and 789 bp for the class 1 and class 2 integrase PCR products $[18,25]$.

\footnotetext{
Acknowledgements

The authors are grateful to the "National Collection of III-IV Group Pathogens" of the Ministry of Health of the Republic of Uzbekistan for providing the isolates. Funding for this study was received from the Uzbekistan state grant (A-9-293) and the Armed Forces Health Surveillance Center - Global Emerging Infections Surveillance Response System (AFHSCGEIS).

Disclaimer

The views expressed in this article are those of the author and do not reflect the official policy of the Department of the Army, Department of Defense, or the U.S. Government.
}

\section{Author details}

${ }^{1}$ Research Institute of Epidemiology, Microbiology and Infectious Diseases, Tashkent 100133, Republic of Uzbekistan. ²Department of Enteric Diseases, Armed Forces Research Institute of Medical Sciences (AFRIMS), 315/6 Rajvithi Road, Bangkok 10400, Thailand.

\section{Authors' contributions}

All authors equally participated in study design, data analysis/interpretation and writing of the manuscript.

\section{Competing interests}

The authors declare that they have no competing interests.

Received: 21 September 2010 Accepted: 9 December 2010 Published: 9 December 2010
References

1. Kotloff KL, Winickoff JP, Ivanoff B, Clemens JD, Swerdlow DL, Sansonetti PJ, Adak GK, Levine MM: Global burden of Shigella infections: implications for vaccine development and implementation of control strategies. Bull World Health Organ 1999, 77:651-666.

2. Legros D: Guidelines for the control of shigellosis, including epidemics due to Shigella dysenteriae 1. Geneva, Switzerland: World Health Organization; 2005

3. Sur D, Ramamurthy T, Deen J, Bhattacharya SK: Shigellosis : challenges \& management issues. Indian J Med Res 2004, 120:454-462.

4. Kapil A: The challenge of antibiotic resistance: need to contemplate. Indian J Med Res 2005, 121:83-91.

5. Ross S, Controni G, Khan W: Resistance of shigellae to ampicillin and other antibiotics. Its clinical and epidemiological implications. JAMA 1972, 221:45-47.

6. Sack RB, Rahman M, Yunus M, Khan EH: Antimicrobial resistance in organisms causing diarrheal disease. Clin Infect Dis 1997, 24(Suppl 1):S102-105.

7. Depardieu F, Podglajen I, Leclercq R, Collatz E, Courvalin P: Modes and modulations of antibiotic resistance gene expression. Clin Microbiol Rev 2007, 20:79-114.

8. Normark BH, Normark S: Evolution and spread of antibiotic resistance. J Intern Med 2002, 252:91-106.

9. Martinez E, de la Cruz F: Genetic elements involved in Tn21 site-specific integration, a novel mechanism for the dissemination of antibiotic resistance genes. EMBO J 1990, 9:1275-1281.

10. Stokes HW, Hall RM: A novel family of potentially mobile DNA elements encoding site-specific gene-integration functions: integrons. Mol Microbiol 1989, 3:1669-1683.

11. Carattoli $\mathrm{A}$ : Importance of integrons in the diffusion of resistance. Vet Res 2001, 32:243-259.

12. Mazel D: Integrons: agents of bacterial evolution. Nat Rev Microbiol 2006, 4:608-620.

13. White PA, Mclver CJ, Rawlinson WD: Integrons and gene cassettes in the enterobacteriaceae. Antimicrob Agents Chemother 2001, 45:2658-2661.

14. DeLappe N, O'Halloran F, Fanning S, Corbett-Feeney G, Cheasty T, Cormican M: Antimicrobial resistance and genetic diversity of Shigella sonnei isolates from western Ireland, an area of low incidence of infection. J Clin Microbiol 2003, 41:1919-1924.

15. Iversen J, Sandvang D, Srijan A, Cam PD, Dalsgaard A: Characterization of antimicrobial resistance, plasmids, and gene cassettes in Shigella spp. from patients in vietnam. Microb Drug Resist 2003, 9(Suppl 1):S17-24.

16. Mammina C, Pontello M, Dal Vecchio A, Nastasi A: Identification of Shigella sonnei biotype $\mathrm{g}$ isolates carrying class 2 integrons in Italy (2001 to 2003). J Clin Microbiol 2005, 43:2467-2470.

17. Sack DA, Lyke C, McLaughlin C, Suwanvanichkij V: Antimicrobial resistance in shigellosis, cholera, and campylobacteriosis (WHO/CDS/CSR/DRS/ 2001.8). Geneva, Switzerland: World Health Organization; 2001.

18. Pan JC, Ye R, Meng DM, Zhang W, Wang HQ, Liu KZ: Molecular characteristics of class 1 and class 2 integrons and their relationships to antibiotic resistance in clinical isolates of Shigella sonnei and Shigella flexneri. J Antimicrob Chemother 2006, 58:288-296.

19. Ranjbar R, Aleo A, Giammanco GM, Dionisi AM, Sadeghifard N, Mammina C: Genetic relatedness among isolates of Shigella sonnei carrying class 2 integrons in Tehran, Iran, 2002-2003. BMC Infect Dis 2007, 7:62.

20. Perilla MJ, Bopp C, Elliott J, Facklam R, Knapp JS, Popovic T, Wells J, Dowell SF: Manual for the laboratory identification and antimicrobial susceptibility testing of bacterial pathogens of public health importance in the developing world: Haemophilus influenzae, Neisseria meningitidis, Streptococcus pneumoniae, Neisseria gonorrhoea, Salmonella serotype Typhi, Shigella, and Vibrio cholerae (WHO/CDS/CSR/RMD/2003.6) Geneva, Switzerland: World Health Organization; 2003.

21. Ewing WH, Edwards PR: Edwards and Ewing's identification of Enterobacteriaceae. 4 edition. New York, NY, USA: Elsevier; 1986.

22. Clinical and Laboratory Standards Institute: Methods for dilution antimicrobial suceptibility tests for bacteria that grow aerobically: approved standard (M7-A7). 7 edition. Wayne, PA, USA: Clinical and Laboratory Standards Institute; 2006.

23. Clinical and Laboratory Standards Institute: Performance standards for antimicrobial susceptibility testing; seventeenth informational supplement (M100-S17) Wayne, PA, USA: Clinical and Laboratory Standards Institute; 2007. 
24. Semina NA, Sidorenko SV, Rezvan SP, Grudinina SA, Strachounski LS, Tsetsuk OU, Kozlov RS, Endelshtein MV, Vedmina EA, Stolyarova LG, et al: Guidelines for susceptibility testing of microorganisms to antibacterial agents. CMAC 2004, 6:306-357.

25. Ploy MC, Denis F, Courvalin P, Lambert T: Molecular characterization of integrons in Acinetobacter baumannii: description of a hybrid class 2 integron. Antimicrob Agents Chemother 2000, 44:2684-2688.

doi:10.1186/1757-4749-2-18

Cite this article as: Madiyarov et al:: Antimicrobial resistance patterns and prevalence of class 1 and 2 integrons in Shigella flexneri and Shigella sonnei isolated in Uzbekistan. Gut Pathogens 2010 2:18.

Submit your next manuscript to BioMed Central and take full advantage of:

- Convenient online submission

- Thorough peer review

- No space constraints or color figure charges

- Immediate publication on acceptance

- Inclusion in PubMed, CAS, Scopus and Google Scholar

- Research which is freely available for redistribution

Submit your manuscript at www.biomedcentral.com/submit
Ciomed Central 